\title{
Evaluating the effect of drill string rotation and change in drilling fluid viscosity on hole cleaning
}

\author{
Samuel Bright Olawale ${ }^{1} \cdot$ Promise O. Longe $^{1}$ (i) $\cdot$ Samuel Felix Ofesi ${ }^{1}$
}

Received: 3 November 2020 / Accepted: 7 June 2021 / Published online: 22 June 2021

(c) The Author(s) 2021

\begin{abstract}
The most primitive hole challenge is cleaning the hole, which is more severe in deviated wells. This problem was tackled in this research via experimental analysis and graphical evaluations. To hit this aim, rheological parameters were experimentally obtained, and Noah's model was used to determine cutting bed erosion time at varying heights. A graphical evaluation was done using a case study of deviated wells X and Y from a Niger Delta field. The result shows that low-viscosity fluid, KCL polymer fluid and high-viscosity fluid take 124, 283 and $342 \mathrm{~min}$, respectively, to erode equal height as graphical evaluation shows that hole cleaning will grow complex on deviation. Thus, the deduction from this work in reducing non-productive time (NPT) related to hole cleaning in drilling operation is first, prior to making a trip, pumping low-viscosity fluid at a high flow rate. Secondly, during drilling, increasing drill string rotation in deviated wells can effectively stir the cuttings into the annulus above the low session of the hole.
\end{abstract}

Keywords Hole cleaning $\cdot$ Drilled cuttings $\cdot$ Cutting transport $\cdot$ Viscosity $\cdot$ Pipe rotation $\cdot$ Deviated wells

\section{Introduction}

Hole cleaning, as one of the most important functions of drilling fluid, is simply defined as the transportation of drilled cuttings from the wellbore to the surface, and at the surface, the drilled cuttings are mechanically separated from the drilling fluid before it is re-circulated. Hence, good hole cleaning is achieved when this drilling fluid effectively circulates the cuttings out of the wellbore. The design of any well is targeted to deal with critical problems of hole cleaning to guarantee drilling success; however, when these key elements are undermined, the inherent drilling risk of these wells increases. As drilling progresses with increasing hole angle, there is a change in the movement of drilled cuttings from vertical to radial, thereby causing Boycott settling effect. As this bed is formed, failure to clear off the cutting bed can cause severe drilling problems such as stuck pipe, bit balling, premature bit wear, drag and excessive torque on the drill string, logging and cementing difficulties. The worst

Promise O. Longe

longepromise@gmail.com

1 Department of Petroleum and Natural Gas Engineering, Federal University of Petroleum Resources, Effurun, Delta, Nigeria of these problems is drill string sticking, which requires expensive remedial actions to solve. This has been the industries craving for the past years to get hole cleaning correctly done, especially for deviated wells. A clear understanding of the cardinal element of high angle hole cleaning must satisfy this question if drilled cuttings flowing over the shale shakers is being cleaned. The question leads to further question like; how fast can the hole cleaning take? Are more cuttings generated inside the wellbore than those being transported out of the wellbore? Is there a way to measure this? The first approach toward answering these questions is to identify key elements that influence hole cleaning efficiency. The elements related to hole cleaning efficiency include hole size, washout, drill pipe diameter, flow rate, rotary speed, mud rheology, well path, cuttings size, pipe reciprocation, sliding, penetration rate, wellbore stability, cuttings dispersion and mud solids. Although all these elements play a role in determining the time taken to transport drilled cuttings out of hole, rotary speed and mud rheology have a singular role in how cuttings are efficiently driven into fluid flow. It is pertinent to note that the efficiency of hole cleaning is based primarily on three factors: flow rate to move cuttings out of the wellbore, rotary speed (drill string rotation) to throw cuttings into the flow regime, and fluid rheology to produce 
viscous couplings; additionally, it helps in cuttings suspension momentarily in the flow regime.

The transportation of cuttings and efficient hole cleaning is indispensable in any drilling program. These have driven researchers to study cuttings transport and hole cleaning to predict hole cleaning efficiency of drilling fluids and optimize a drilling program. Besides, these have helped to reduce the problems encountered and cost during drilling operations. In the process, correlations and charts have been developed. These are either based on experiments, termed as empirical approach or theoretical known as mechanistic approach. Williams and Bruce (1951) deduced from their experiments that the carrying capacity of drilling mud was increased when the mud weight increased and the viscosity was lowered. This was followed by Zeidler (1970), whose experiments concluded that increased particle's transport was due to pipe rotation and turbulent stresses in fluid rather than to the flat velocity profiles in a turbulent flow.

Tomren et al. (1986) conducted an experimental study on a total of 242 different tests with different pipe inclination, pipe eccentricities coupled with varying fluid flow regimes (laminar and turbulent) to study transportation of drilled cuttings in directional wells. A $40 \mathrm{ft}$. pipe, range of annular angles from $0^{\circ}$ to $90^{\circ}$ and actual drilled cuttings were used to carry out the investigation. It was discovered that a growing formation cuttings bed reduced the effective flow area at high liquids rates for angles that were greater than $40^{\circ}$. Their work proved that higher viscosity fluid would transport drilled cuttings better under laminar flow regime. Also, transport performance in an inclined wellbore is slightly influenced by pipe rotation.

Okrajni and Azar (1986) investigated the impacts of mud rheology on hole cleaning for the annulus in deviated wells. The experiment zeroed in on mud yield point [YP], plastic viscosity [PV] and YP/PV proportion. Three separate locales for cuttings transport, in particular $0^{\circ}$ to $45^{\circ}, 45^{\circ}$ to $55^{\circ}$ and $55^{\circ}$ to $90^{\circ}$, were recognized. They suggested a laminar stream for the hole cleaning in a section between $0^{\circ}$ and $45^{\circ}$ and a turbulent flow for hole cleaning in a span of $55^{\circ}$ and $90^{\circ}$.

Gavignet and Sobey (1989) introduced a cutting transport mechanistic approach. A two-layer model was built for cuttings transport in an eccentric annulus with non-Newtonian drilling fluid. They found a critical rate above which there will be no bed formation, and that happens when the flow stream was in a turbulent stage. The investigation demonstrated that this measure was emphatically reliant on drillpipe eccentricity, cuttings size, hole diameter and drill-pipe outer diameter. Unexpectedly, the characterized critical rate was somewhat subject to rheology, rate of penetration and angle of inclination greater than $60^{\circ}$. It also showed that the contact coefficient of the cuttings against the wellbore influenced the formation of beds at high points of deviation profoundly.

Sifferman and Becker (1990) experimented on the effects of various parameters on the transportation of drilled cuttings in full vertical annuli. They reported that the cutting's transport efficiency was controlled by annular velocity, rheological properties such as the fluid viscosity and density, cutting size, flow regime with little dependence on casing size, pipe rotation, drilling rate and drill pipe eccentricity.

Ford et al. (1990) led a test investigation of transportation of drilled cuttings in a slanted wellbore. Two distinct cuttings transport mechanisms were introduced in their exploration: First, the cuttings were moved to the surface by a rolling or sliding movement along the most minimal or lowest side of the annulus, and then the cuttings were moved in suspension in the circulating fluid. The principal contrast between these two mechanisms was that the latter mechanism required a higher liquid speed than the first. They recognized minimum transport velocity (MTV), subject to various parameters, such as drilling fluid rheology, pipe eccentricity, annular fluid velocity, hole angle and cuttings size. Additionally, they saw that increased viscosity of circulating fluid would promptly diminish MTV of cuttings for rolling and suspension structure. The test showed that in a turbulent flow stream, water was an exceptionally viable transport fluid.

Peden et al. (1990) introduced an experimental technique, which researched the impact of various factors in cuttings transport, for example, hole angle, cuttings size, drill pipe eccentricity, fluid rheology, circulation ratio, drill-pipe rotation and annular size on the efficiency of cuttings transport utilizing the idea of MTV. The idea assumed that at lower MTV, a wellbore would be cleaned all the more successfully. They reasoned that hole angle strongly affected opening cleaning. They likewise characterized that hole angles somewhere between $40^{\circ}$ and $60^{\circ}$ degrees were the most noticeably arduous angles for cuttings transport for rolling and suspension structures. The perceptions indicated that more modest concentric annuli required a lower MTV for hole cleaning than bigger ones, and successful cleaning of the hole was emphatically reliant on the force of the turbulent flow stream in the annulus. Also, the rotation of pipe appeared not to affect hole cleaning. At all wellbore inclinations, smaller cuttings were moved most adequately when the fluid viscosity was low. In the span point somewhere in the range of $0^{\circ}$ and $50^{\circ}$, huge cuttings were moved all the more successfully with high-viscous drilling fluid. Models for cuttings transport were developed based on the forces acting on the cuttings being moved upward in drilling mud.

Luo et al. (1994) investigated the rate of flow rate predictions for cleaning deviated wells. They built up a forecast model for critical flow rate or the base stream rate needed to eliminate cuttings from the low side of the wellbore or to 
forestall cuttings gathering on the low side of the annulus in deviated wells. The model was validated by experimental data gotten from an 8-inches wellbore. A model and a computer program application were created during their investigation to predict the minimum flow rate for hole cleaning in deviated wells. A later version of the model was rearranged into a progression of charts to encourage rig-site applications.

Azar and Sanchez (1997) study explained essential factors that affect hole cleaning and their field limitations. These factors include annular drilling fluid velocity, annular eccentricity, rate of penetration, hole inclination angle, drill string rotation, properties of drilled cuttings. This study showed and discussed the existing limitations on all these factors as regards hole cleaning. As a result, proper planning and simultaneous optimization of these variables were necessary. Furthermore, the study describes hole cleaning in deviated wells as a complex problem with many issues that had to be addressed before an optimum solution to hole cleaning problems could be presented.

Yu et al. (2004) conducted a study on improving drilled cuttings transport capacity in a horizontal wellbore by investigating the effects of chemical surfactants attached with air bubbles to cutting particles. The strength of attachments between air bubbles and drill cuttings was discovered to have been increased by certain chemical surfactants.

Mirhaj et al. (2007) presented detailed results of a comprehensive experimental study on developing a cuttings transport model for highly deviated wellbores. The study was targeted to determine the minimum transport velocity required for complete cuttings transportation out of the wellbore and the influence of flow rate, rheological properties of mud, mud weight inclination angle, cuttings size, drill pipe eccentricity, and rate of penetration.

Ozbayoglu et al. (2008) concluded in their study that cuttings transport is improved significantly by pipe rotation, especially when the pipe experiences orbital motion. Moreover, the critical fluid velocity needed to remove stationary cuttings bed completely is drastically reduced due to pipe rotation. Particularly, for a single-phase flow, increasing pipe rotation speed causes the frictional pressure losses to increase. However, as the cuttings are introduced, there is a reduction in frictional pressure losses as rotary speed increases due to the reduced stationary cuttings bed area.

Noah (2013) conducted an experimental study to determine the erosion process of cuttings bed under different drilling fluid rheological properties and flow rates. From his model, the rate of cuttings bed erosion rate in the annulus is described by the nonlinear exponential model in Eq. 3.

It has been recommended that transportation of cutting is made simpler within sight of drill pipe rotation. Semisolidified beds can now and again be taken out in light of the fact that the drill string hauls a huge bite of the bed around from the lower part of the annulus to the top, where a high stream rate is. The high stream rate would then disperse the eliminated cuttings somewhat, and great gap cleaning might be accomplished. This behavior is especially an opportunity to eliminate sand beds and other non-receptive cutting particles (Saasen and Løklingholm 2002). Rotation of pipe tends to cause turbulent flow, and this type of flow motion does lead to increased frictional loss. This frictional loss results in increased shear stress on the cutting bed surface, which can further help in cutting removal due to increased shear stress.

Furthermore, there have been propositions that transportation of cuttings is made simpler within sight of drill pipe turn. Past analyses have demonstrated that at $150 \mathrm{rpm}$ pipe revolution, the cuttings are viably blended into the stream system. As a result, the cuttings experienced upward movement as gravity pulls them back out of the flow stream, and the movement of the pipe pushes them up. It is not simply the rotation of pipe that drives the cuttings into the stream system, however, the mix of high rotating speed, pipe eccentricity and mud rheology. The greater part of the hole cleaning happens over the drill pipe tube; the high rotating speed and the viscous coupling between the drilling fluid and the drill pipe make the flow stream spine around the pipe. This flow motion gets the cuttings and conveys them into the flow regime at the hole top. Without this gooey coupling, hole cleaning in a laminar flow climate is slightly decreased. Subsequently, pipe rotational speed guarantees the exchange of energy from the pipe to the drilling fluid and afterward to the cuttings - the better the exchange of energy to the cuttings, the better the hole cleaning. In any case, the significance of pipe rotational speed cannot be ignored as it is the essential methods for moving cuttings into the flow system.

From the reviews shown above, it can be noted that several works have been done on hole cleaning, various contributions, postulations and techniques have been made regarding the effective cleaning of the hole. Furthermore, these techniques are added to the conventional hole cleaning practices, yet, we still experience stuck pipe incidence in the industry. So, the objective of this study is to functionally evaluate the effect of low-viscosity fluid and drill string rotation on hole cleaning. In this research work, emphasis will be laid on fluid rheology and rotary speed, which are the primary focus of this work as the combination of these two helps to provide good hole cleaning in the lower angle of the wellbore. To evaluate these effects, Noah (2013) model will determine the cutting bed erosion time for each drilling fluid.

\section{Materials and methods}

In this study, an estimated volume of $1200 \mathrm{ml}$ of potassium chloride $(\mathrm{KCl})$ polymer base drilling fluid was formulated in the laboratory, see Table 1. After mixing bentonite and 
Table 1 Materials and the quantities needed to formulate potassium chloride $(\mathrm{KCl})$ polymer drilling fluid

\begin{tabular}{llll}
\hline & Materials & Functions & Quantity (ml) \\
\hline 1 & Bentonite (pre-mixed with $\left.\mathrm{H}_{2} \mathrm{O}\right)$ & Viscosifier & 138 \\
2 & Chrome lignosulphate & Fluid loss addictive & 28 \\
3 & Caustic soda & pH control addictive & 8 \\
4 & Potassium chloride & Weighting material, base fluid & 963 \\
5 & Polyanionic cellulose & Filter loss reducer & 55 \\
6 & Potassium hydroxide & pH control addictive & 8 \\
Total volume & & & 1200
\end{tabular}

Table 2 Data from typical well X and Y Niger Delta field

\begin{tabular}{|c|c|c|}
\hline \multirow[t]{2}{*}{ Drill string rotation (RPM) } & \multicolumn{2}{|c|}{$\begin{array}{l}\text { Improvement in cuttings transport rate } \\
\%\end{array}$} \\
\hline & @ 65 degrees (Well X) & $\begin{array}{l}@ 71.8 \\
\text { degrees } \\
\text { (Well Y) }\end{array}$ \\
\hline 0 & 0 & 0 \\
\hline 30 & 32.5 & 12.5 \\
\hline 55 & 42 & 22 \\
\hline 80 & 48 & 34 \\
\hline 105 & 52.5 & 42.5 \\
\hline 130 & 57.5 & 49 \\
\hline 150 & 59 & 52 \\
\hline 175 & 60 & 55 \\
\hline
\end{tabular}

water, it was stirred for $5 \mathrm{~min}$. The base material $(\mathrm{KCl})$ and all other additives were added, the mixture was stirred for $15 \mathrm{~min}$ to formulate the potassium chloride $(\mathrm{KCl})$ polymer drilling fluid. After the fluid preparation, its viscosity varied from high to low. Rheological properties of the formulated drilling fluids were tested using a Fann viscometer, and acquired data were input into an existing hole cleaning model (Noah 2013) to evaluate the effectiveness of the three formulated drilling fluids.

- The high-viscosity fluid was prepared by dissolving $8.8 \mathrm{~g}$ of $2.35 \mathrm{~g}$ per milliliter of Bentonite clay into a $1200 \mathrm{ml}$ volume of already prepared potassium chloride $(\mathrm{KCl})$ polymer drilling fluid. The mixture was agitated for $15 \mathrm{~min}$.

- The low-viscosity drilling fluid was formulated from the existing $1200 \mathrm{ml}$ volume of based fluid by diluting $473 \mathrm{ml}$ of $7.3 \mathrm{lb}$ per gallon potassium chloride into the potassium chloride $(\mathrm{KCl})$ polymer drilling fluid. The mixture was agitated for $15 \mathrm{~min}$.
However, data obtained from a typical well $\mathrm{X}$ and $\mathrm{Y}$ Niger Delta field will be used in evaluating the effect of pipe rotation on hole cleaning. See Table 2.

\section{Experimental procedure for rheological properties}

The rheological properties of the formulated drilling fluids were tested in the laboratory at ambient temperature $\left(82^{\circ}\right.$ F) using Fann viscometer for shear readings of $600 \mathrm{rpm}$, $300 \mathrm{rpm}, 6 \mathrm{rpm}, 3 \mathrm{rpm}$, and $10 \mathrm{~min}$ and $10 \mathrm{~s}$ Gel. The procedures are thus aligned below:

1. The potassium chloride $(\mathrm{KCl})$ polymer drilling fluid sample was filled in the stainless steel sample test cup of the Fann viscometer to the scribed line and placed on the instrument stage.

2. The knurled knob of the viscometer was loosened, and the instrument stage with the stainless steel in it was raised until the rotor was immersed to the scribed line, which is the proper immersion depth of the stainless steel cup. Hence, the knurled knob was tightened.

3. The rotor of the viscometer was operated in a high-speed position of $600 \mathrm{rpm}$ with the gear shifted down. When the dial reading on the viscometer became stabilized, the measurement shown on the indicator was recorded.

4. The rotor of the viscometer was then switched to $300 \mathrm{rpm}$ speed with the gear still shifted down. The dial reading on the viscometer was also recorded when the indicator became steady.

5. The rotor of the viscometer was then switched to $6 \mathrm{rpm}$ speed with the gear still shifted down. The dial reading on the viscometer was also recorded when the indicator became steady.

6. The rotor of the viscometer was then switched to $3 \mathrm{rpm}$ speed with the gear still shifted down. The dial reading on the viscometer was also recorded when the indicator became steady.

7. The RPM knob was turned to the STOP position for the desired rest time, normally $10 \mathrm{~s}$ and $10 \mathrm{~min}$. The RPM knob was however turned to the GEL position after the desired times had been reached. 
8. In units $1 \mathrm{lb} . / 100 \mathrm{ft} 2$, the gel strength was measured by taking the maximum dial deflection when the rotational viscometer was turned at low rotor speed (i.e., $3 \mathrm{rpm}$ ).

9. The plastic viscosity and the yield of the drilling fluid samples were obtained using Eqs. (1) and (2).

$$
\begin{aligned}
& \mathrm{PV}=\theta_{600}-\theta_{300} \\
& \mathrm{YP}=\theta_{300}-\mathrm{PV} \\
& \text { where } \mathrm{PV}=\text { plastic viscosity }(\mathrm{cp}) \\
& \mathrm{YP}=\text { yield point, } \mathrm{lb} / 100 \mathrm{ft}^{2} \\
& \theta_{600 \mathrm{rpm}}=\text { dial reading of viscometer at } 600 \mathrm{rpm} . \\
& \theta_{300 \mathrm{rpm}}=\text { dial reading of viscometer at } 300 \mathrm{rpm} .
\end{aligned}
$$

The values of the measured properties are recorded in Table 3. The same experimental procedures were carried out for low- and high-viscosity drilling fluid, and their rheological properties were measured and recorded as shown in Tables 4 and 5 as follows.

\section{Optimum hole cleaning model}

The approach implored in this study to evaluate the effectiveness of the three formulated drilling fluid on hole cleaning involved the following model (Table 6).

Noah (2013) conducted an experimental study to determine the erosion process of cuttings bed under different drilling fluid rheological properties and flow rates. From his model, the rate of cuttings bed erosion rate in the annulus is described by the nonlinear exponential model as Eq. (3):

$H_{(t)}=\alpha+\beta e^{-\gamma t}$

where

$\alpha=$ Height of residual bed (bed height corresponding to infinite circulation time).

$\beta=$ Height of initial cuttings bed - Height of residual bed.

$\gamma=$ Reciprocal of time constant

Table 3 The rheological result for potassium chloride $(\mathrm{KCl})$ polymer drilling fluid

\begin{tabular}{ll}
\hline Parameters & Values \\
\hline Shear rate at $600 \mathrm{rpm}$ & 44 \\
Shear rate at $300 \mathrm{rpm}$ & 31 \\
Shear rate at $6 \mathrm{rpm}$ & 13 \\
Shear rate at $3 \mathrm{rpm}$ & 11 \\
Shear rate at $10^{\prime} / 10^{\prime \prime}$ Gel & $11 / 13 \mathrm{lbs} / 100 \mathrm{ft}^{2}$ \\
Viscosity & $49 \mathrm{cp}$ \\
Plastic viscosity & $13 \mathrm{mPa} . \mathrm{s}$ \\
Yield point & $18 \mathrm{lb} / 100 \mathrm{ft}^{2}$ \\
Mud weight & $8.6 \mathrm{ppg}$ \\
\hline
\end{tabular}

Table 4 The rheological result for low-viscosity drilling fluid

\begin{tabular}{ll}
\hline Parameters & Values \\
\hline Shear rate at $600 \mathrm{rpm}$ & 39 \\
Shear rate at $300 \mathrm{rpm}$ & 27 \\
Shear rate at $6 \mathrm{rpm}$ & 10 \\
Shear rate at $3 \mathrm{rpm}$ & 7 \\
Shear rate at $10^{\prime} / 10^{\prime \prime} \mathrm{Gel}$ & $7 / 10 \mathrm{lbs} / 100 \mathrm{ft}^{2}$ \\
Viscosity & $38 \mathrm{cp}$ \\
Plastic viscosity & $12 \mathrm{mPa.s}$ \\
Yield point & $151 \mathrm{~b} / 100 \mathrm{ft}^{2}$ \\
Mud weight & $8.4 \mathrm{ppg}$ \\
\hline
\end{tabular}

$\gamma=\frac{n}{k}$

$n=0.5 \log \frac{\theta_{300}}{\theta_{600}}$

$n=$ fluid flow behavior index.

$K=$ fluid consistency index

$K=5.11 \frac{\theta_{300}}{511^{n}}$

Then, he proposed the final bed erosion model defined as:

$h=f$ (high Flow Rate, Drilling Fluid Properties, Time)

In the regression analysis, Noah fitted regression coefficients of $\alpha, \beta$ and $\gamma$ with flow rate and drilling fluid properties ( $\mathrm{n}$ and $\mathrm{K}$ values of a Power Law model). He relates $\alpha$ and $\gamma$ to flow rate mathematically by a logarithmic function expressed as:

$\alpha=-\lambda \ln (Q)+(\Psi)$

Table 5 The rheological result for high-viscosity drilling fluid

\begin{tabular}{ll}
\hline Parameters & Values \\
\hline Shear rate at $600 \mathrm{rpm}$ & 56 \\
Shear rate at $300 \mathrm{rpm}$ & 41 \\
Shear rate at $6 \mathrm{rpm}$ & 18 \\
Shear rate at $3 \mathrm{rpm}$ & 14 \\
Shear rate at $10^{\prime} / 10^{\prime \prime}$ Gel & $14 / 18 \mathrm{lbs} / 100 \mathrm{ft}^{2}$ \\
Viscosity & $66 \mathrm{cp}$ \\
Plastic viscosity & $15 \mathrm{mPa} . \mathrm{s}$ \\
Yield point & $261 \mathrm{~b} / 100 \mathrm{ft}^{2}$ \\
Mud weight & $8.9 \mathrm{ppg}$ \\
\hline
\end{tabular}


Table 6 The summary of the result of drilling fluids rheology properties using Noah's model

\begin{tabular}{|c|c|c|c|c|}
\hline \multirow[t]{2}{*}{ Variables } & \multirow[t]{2}{*}{ Formula } & \multicolumn{3}{|c|}{ Drilling fluid types } \\
\hline & & $\begin{array}{l}\mathrm{KCl} \text { polymer } \\
\text { drilling fluid }\end{array}$ & $\begin{array}{l}\text { High-viscos- } \\
\text { ity drilling } \\
\text { fluid }\end{array}$ & $\begin{array}{l}\text { Low-viscos- } \\
\text { ity drilling } \\
\text { fluid }\end{array}$ \\
\hline \multirow[t]{2}{*}{ Drilling rheology parameters } & Fluid flow behavior index ' $n$ ' & 0.2250 & 0.2333 & 0.2931 \\
\hline & Fluid Consistency Index 'k' & 38.9430 & 48.8939 & 22.1746 \\
\hline Inverse viscosity function ' $\gamma$ ' & $\frac{n}{k}$ & 0.0058 & 0.0048 & 0.0132 \\
\hline PV (cp) & $P V=\theta_{600}-\theta_{300}$ & 13 & 15 & 12 \\
\hline $\mathrm{YP}\left(\mathrm{Ib} / 100 \mathrm{ft}^{2}\right)$ & $\mathrm{YP}=\theta_{600 \mathrm{rpm}}-\mathrm{PV}$ & 18 & 26 & 15 \\
\hline MW (ppg) & & 8.6 & 8.9 & 8.4 \\
\hline $\begin{array}{l}\text { Noah (2013) model for cut- } \\
\text { ting bed erosion time ( } \mathrm{min} \text { ) }\end{array}$ & $t=-\frac{1}{\gamma} \ln \frac{(h(t)-\alpha)}{\beta}$ & 283 & 342 & 124 \\
\hline
\end{tabular}

$-\gamma=-\sigma \ln (Q)+(w)$

where the following equation gives the relationship between $\alpha$ and $\beta$ :

$\beta=h^{\prime}(0)-\alpha$

Here, $h$ '(0) is the height initial bed determined by the drilling conditions (just before the tripping operation begins) passing to circulation. Also, $h^{\prime}(0)$ can be determined empirically. The coefficients $\lambda, \psi, \sigma$, and $\omega$ are dependent on the rheological properties of drilling fluid and wellbore inclination.

For each fluid properties, he determined the time required for complete removal of cutting bed and their coefficients $\alpha$, $\beta$ and $\gamma$ as shown in the equation below a for conventional drilling fluid.

$h_{(t)}=-0.445+5.405 e^{-\gamma t}$

\section{Results}

Tables 3, 4 and 5 show the results from the rheological test carried out for the three drilling fluids.

\section{Discussions}

The effect of change in drilling fluid rheological properties with respect to hole cleaning can be further explained from the results obtained from the three models. However, the data acquired from typical wells $\mathrm{X}$ and $\mathrm{Y}$ in Niger Delta fields are further explained as follows.

When these three different fluids rheological properties were also inputted into the mathematical model of the time taken for cutting bed erosion as proposed by Noah (2013), it was observed that the time taken to erode a 5.0 inches cutting bed height for low-viscosity fluid was $124 \mathrm{~min}$, for $\mathrm{KCl}$ polymer drilling fluid was $283 \mathrm{~min}$ and for high-viscosity fluid was $342 \mathrm{~min}$.

Figure 1 above is a graphical representation of the result obtained from Noah's model. From the graph, it was observed that it took the low-viscosity fluid (case-2) $124 \mathrm{~min}$ to erode a 5 -inch cutting bed to 0.6 inches, while case- 1 (base fluid) and case-3 (high-viscosity fluid) took longer erosion time. The graph in Fig. 1 shows that low-viscosity fluid at a fixed flow rate is very effective in eroding cutting bed faster. The lighter the drilling fluid, the lesser the cutting bed erosion time and vice versa.

Cutting bed erosion time is hence calculated using the formula below. See Appendix Table 7 for table

$t=-\frac{1}{\gamma} \ln \frac{(h(t)-\alpha)}{\beta}$

\section{Drill pipe rotation}

See Table 2. With acquired data, cuttings transport collected at the shale shaker are evaluated with respect to the drill string rotation, rpm. The graphs obtained from this evaluation are shown as follows.

From Fig. 2, the chart implies that as drill string rpm increases, the percentage or rate of cuttings transport increases also. Hence, cutting bed decreases as drill string rpm increases. See the following Fig. 3. However, an increase in drill string rpm cannot result in an equal increase in cuttings transport. Thus, it results in a geometric decrease in cuttings transport rate interval. At $175 \mathrm{rpm}$, the cuttings transport rate for 65 degrees angle differs from the cuttings transport rate at 71.8 degree angle by $5 \%$, which shows that the higher the hole deviation, the lesser the cuttings return on shale shaker. Hence, if a low-viscosity fluid is used, 


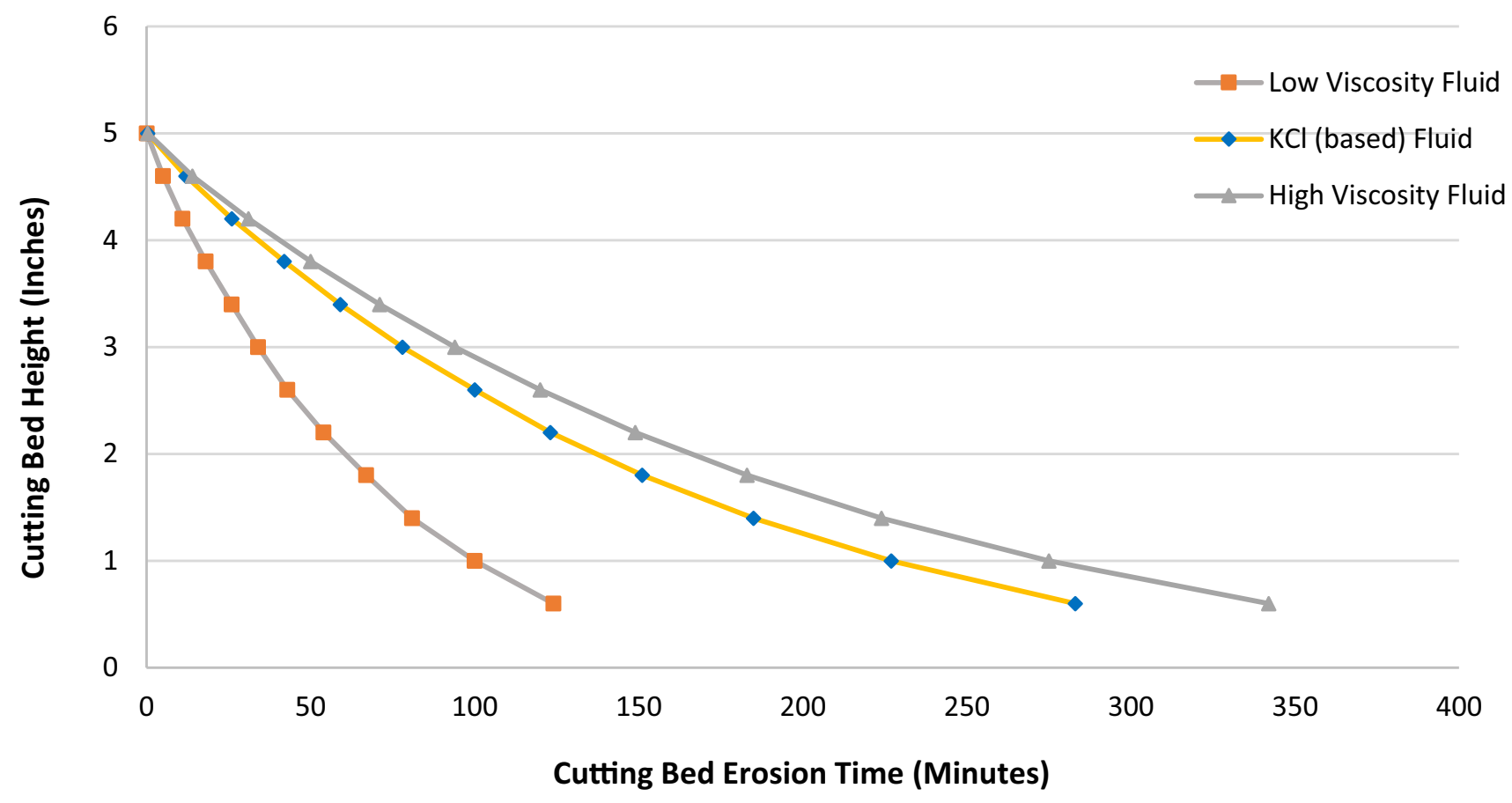

Fig. 1 Graph of cutting bed height against cutting bed erosion time

\section{Improvement in cuttings transport at 65 \& 71.8 degrees angle}

(\%)

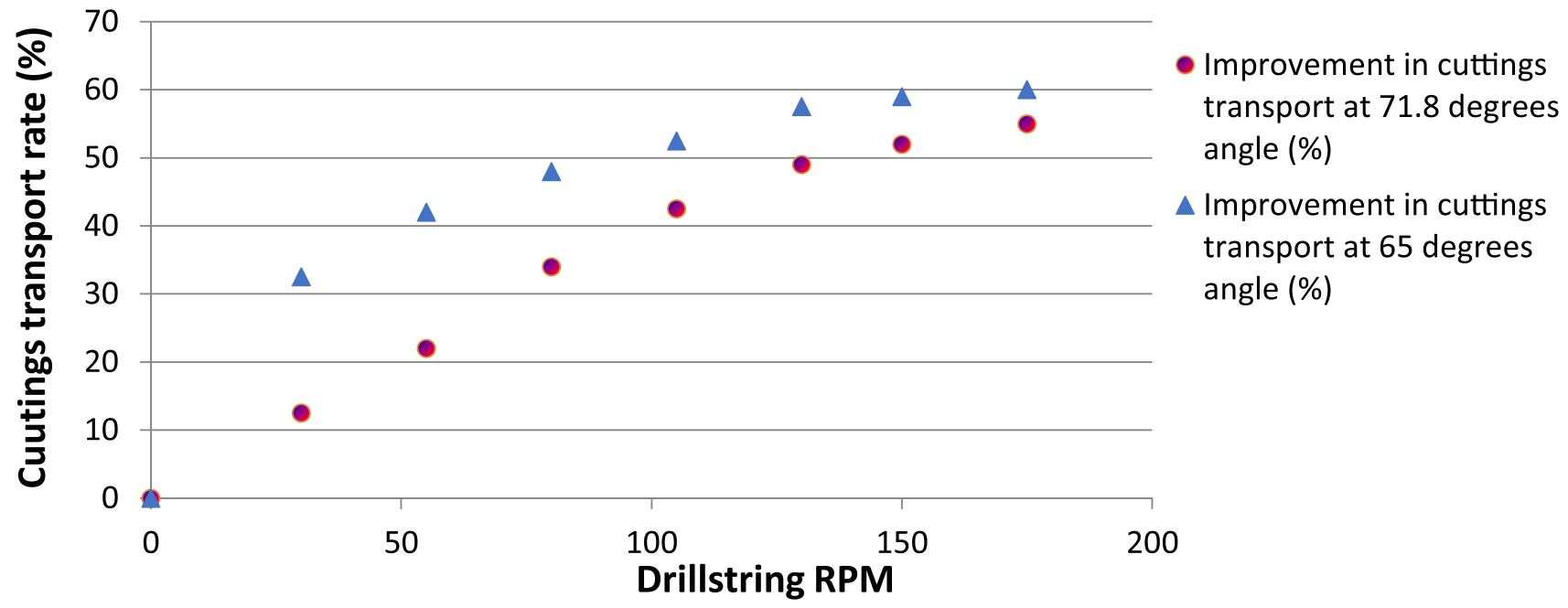

Fig. 2 Improvement in cuttings transport for deviated well at different angles

the percentage of cuttings return would have been higher because of its high-viscous coupling, transporting more cuttings to the shale shaker at the surface. This was the major limitation of this research.

From these results:
- Low-viscosity drilling fluid will take less than $45 \%$ of the time needed by the other drilling fluids. With these, the fastest way to erode cutting bed can be achieved if a lowviscosity drilling fluid is pumped at an optimum flow rate. 


\section{IMPROVEMENT OF DRILL STRING RPM ON CUTTING BED HEIGHT}

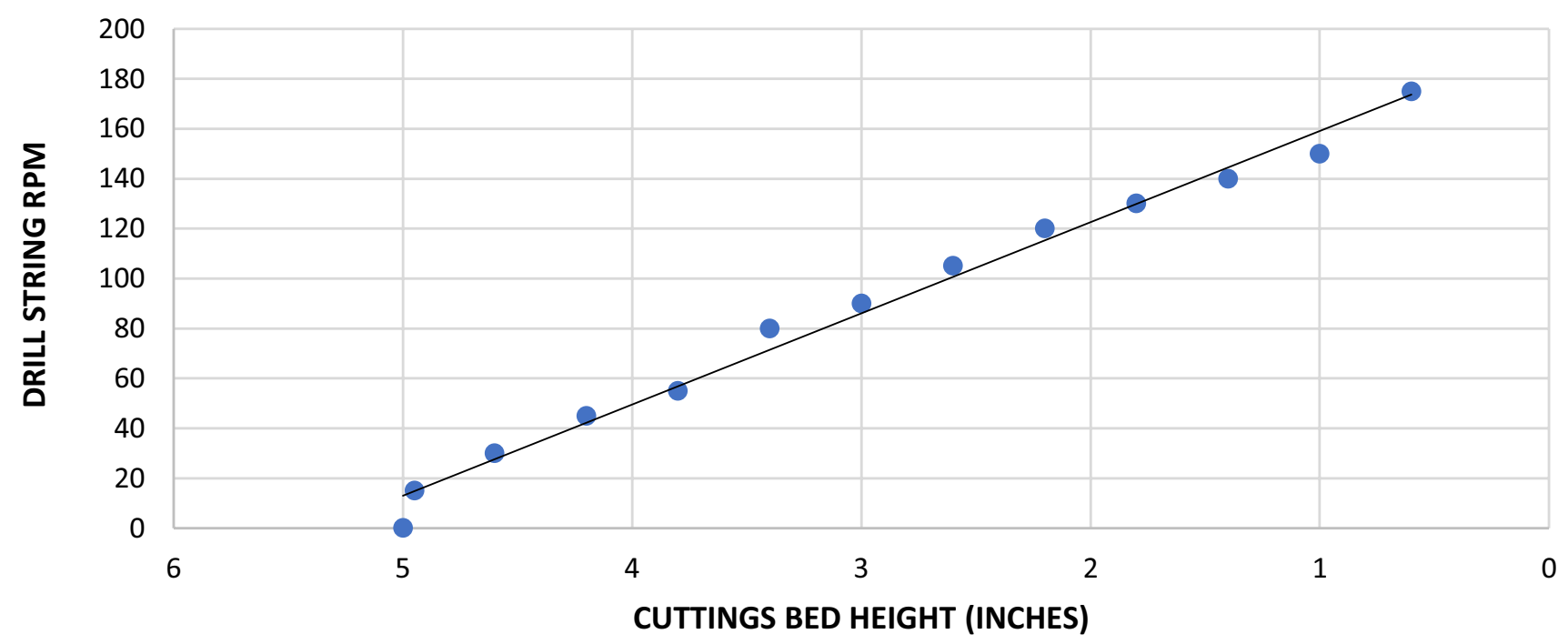

Fig. 3 Improvement of drill string rotation on cutting bed height

- The higher the hole deviation, the lesser the cuttings return on shale shaker. Hence, cutting bed decreases as drill string rpm increases.

\section{Conclusion}

To sum up, from this research work, the following conclusions can be drawn:

Firstly, an excellent way of reducing non-productive time (NPT) related to hole cleaning in drilling operation:

- Prior to making a trip, pump low-viscosity fluid at a high flow rate.

- While drilling, increase drill string rotation in deviated wells to effectively stir the cuttings into the annulus above the low session of the hole.

Also, low-viscosity fluid is faster in cutting bed erosion; applying it prior to tripping will save rig time. Furthermore, the drill string's high rotating speed will help save rig time as the cutting transport rate increases. Hence, the probability of successful completion of a well is enhanced.

\section{Recommendation}

From this research work, the following recommendations can be made:
1. Similar work should be done for oil base fluid.

2. Real-time practical should be done to study the effect of low-viscosity fluid at varying drill string RPMs on hole cleaning simultaneously for deviated wells as this was the limitation of this project.

\section{Appendix}

This appendix shows the values used in plotting the various Figs. 1, 2 and 3 (see Tables 7, 8 and 9).

Table 7 Table showing the values for plotting Fig. 1

\begin{tabular}{|c|c|c|c|}
\hline \multirow{2}{*}{$\begin{array}{l}\text { Cutting bed height } \\
\text { (inches) }\end{array}$} & \multicolumn{3}{|c|}{ Bed erosion time $(\min )$} \\
\hline & $\begin{array}{l}\text { Low-viscosity } \\
\text { fluid }\end{array}$ & $\begin{array}{l}\mathrm{KCl} \text { (based) } \\
\text { fluid }\end{array}$ & $\begin{array}{l}\text { High- } \\
\text { viscosity } \\
\text { fluid }\end{array}$ \\
\hline 5.0 & 0.1 & 0.3 & 0.4 \\
\hline 4.6 & 5 & 12 & 14 \\
\hline 4.2 & 11 & 26 & 31 \\
\hline 3.8 & 18 & 42 & 50 \\
\hline 3.4 & 26 & 59 & 71 \\
\hline 3.0 & 34 & 78 & 94 \\
\hline 2.6 & 43 & 100 & 120 \\
\hline 2.2 & 54 & 123 & 149 \\
\hline 1.8 & 67 & 151 & 183 \\
\hline 1.4 & 81 & 185 & 224 \\
\hline 1.0 & 100 & 227 & 275 \\
\hline 0.6 & 124 & 283 & 342 \\
\hline
\end{tabular}


Table 8 Table showing the values for plotting Fig. 2

\begin{tabular}{lll}
\hline $\begin{array}{l}\text { Drill string rotation } \\
\text { (RPM) }\end{array}$ & \multicolumn{2}{l}{ Improvement in cuttings transport rate \% } \\
\cline { 2 - 3 } & @ 65 degrees & @ 71.8 degrees \\
\hline 0 & 0 & 0 \\
30 & 32.5 & 12.5 \\
55 & 42 & 22 \\
80 & 48 & 34 \\
105 & 52.5 & 42.5 \\
130 & 57.5 & 49 \\
150 & 59 & 52 \\
175 & 60 & 55 \\
\hline
\end{tabular}

Table 9 Table showing the values used for plotting Fig. 3

\begin{tabular}{ll}
\hline $\begin{array}{l}\text { Cutting bed } \\
\text { height (inches) }\end{array}$ & $\begin{array}{l}\text { Drill string } \\
\text { rotation } \\
\text { (rpm) }\end{array}$ \\
\hline 5 & 0 \\
4.95 & 15 \\
4.6 & 30 \\
4.2 & 45 \\
3.8 & 55 \\
3.4 & 80 \\
3 & 90 \\
2.6 & 105 \\
2.2 & 120 \\
1.8 & 130 \\
1.4 & 140 \\
1 & 150 \\
0.6 & 175 \\
\hline
\end{tabular}

Financial disclosure statement The authors received no specific funding for this work.

\section{Declarations}

Conflict of interest On behalf of all the co-authors, the corresponding author states that there is no conflict of interest.

Open Access This article is licensed under a Creative Commons Attribution 4.0 International License, which permits use, sharing, adaptation, distribution and reproduction in any medium or format, as long as you give appropriate credit to the original author(s) and the source, provide a link to the Creative Commons licence, and indicate if changes were made. The images or other third party material in this article are included in the article's Creative Commons licence, unless indicated otherwise in a credit line to the material. If material is not included in the article's Creative Commons licence and your intended use is not permitted by statutory regulation or exceeds the permitted use, you will need to obtain permission directly from the copyright holder. To view a copy of this licence, visit http://creativecommons.org/licenses/by/4.0/.

\section{References}

Azar J, Sanchez A (1997) Important issues in cuttings transport for drilling directional wells. In: Fifth Latin American and Caribbean Petroleum Engineering Conference, Rio de Janeiro, 1997

Ford J, Gao E, Oyeneyin M, Peden J, LarruciaM, Parker D (1990) A New MTV Computer Package for Hole-Cleaning Design and Analysis. In: SPE Petroleum Computer Conference, July 11-14, New Orleans.

Gavignet AA, Sobey IJ (1989) Model aids cuttings transport prediction. J Petrol Technol, pp 916-921.

Luo Y, Bern P, Chambers B, Kellingray D (1994) Simple charts to determine hole cleaning requirements in deviated wells. In: SPE/ IADC Drilling Conference, February 15-16, Dallas.

Mirhaj S, Shadizadeh S, Fazaelizadeh M (2007) Cuttings removal simulation for deviated and horizontal wellbores. In: 15th SPE Middle Oil \& Gas Show and Conference, March 11-14, Bahrain.

Noah AZ (2013) Optimizing drilling fluid properties and flow rates for effective hole cleaning at high-angle and hhorizontal wells. J Appl Sci Res 9(1):705-718

Okrajni S, Azar J (1986) The effects of mud Rheology on annular hole cleaning in directional wells. SPE Drilling Completion J, pp. 297-308, 1986

Ozbayoglu M, Saasen A, Sorgun M, Svanes (2008) Effect of Pipe rotation on hole cleaning for water-based drilling fluids in horizontal and deviated wells. In: Asia Pacific Drilling Technology Conference and Exhibition, November 25-27, Jarkata, Indonesia, 2008.

Peden J, Ford J, Oyeneyin M (1990) Comprehensive experimental investigation of drilled cuttings transport in inclined wells including the effects of rotation and eccentricity. In: Europec 1990. Hague, Netherlands

Saasen A, Løklingholm G (2002) The effect of drilling fluid rheological properties on hole cleaning. In: IADC/SPE Drilling Conference, 2002

Sifferman T, Becker T (1990) Hole cleaning in full-scale inclined wellbores. In: SPE 65th Annual Technical Conference. Louisiana, USA, New Orleans

Tomren PH, Iyoho AW, Azar JJ (1986) Experimental study of cuttings transport in directional wells. SPE Drilling Engineering, pp 43-56.

Yu M, Melcher D, Takach N, Miska SZ, Ahmed R (2004) A new approach to improve cuttings transport in horizontal and inclined wells. In: SPE Annual Technical Conference and Exhibition, September 26-29, Houston.

Williams CEJR, Bruce GH (1951) Carrying capacity of drilling mud. AIME, pp 111-120

Zeidler UH (1970) An experimental analysis of the transport of drilled particles. SPE Drilling Engineering.

Publisher's Note Springer Nature remains neutral with regard to jurisdictional claims in published maps and institutional affiliations. 